\title{
Toxoid Vaccine
}

National Cancer Institute

\section{Source}

National Cancer Institute. Toxoid Vaccine. NCI Thesaurus. Code C96398.

Any vaccine that contains an inactivated toxic substance used for disease prophylaxis or to vaccinate against snake bites. 